\title{
THERMAL BALLOON ENDOMETRIAL ABLATION: A SAFE AND EFFECTIVE MODALITY FOR TREATMENT OF DYSFUNCTIONAL MENORRHAGIA
}

\section{Osama Shawki, Ashraf Younis, Mohamad I. El Bokl, and Gamal Eid.}

Department of obstetrics and gynecology, Faculty of medicine, Cairo University

\section{ABSTRACT}

Study Objectives : Evaluation of safety, effectiveness and short-term results of thermal balloon endometrial ablation in treatment of dysfunctional menorhagia.

Setting : Inpatient section of obstetrics and gynecology department at Cairo University hospitals. The study extended from January 2002 to December 2003.

Patients : twenty-four patients with dysfunctional menorragia that met the inclusion criteria.

Intervention : Endometrial thermal ablation using the THERMACHOICE thermal balloon system.

Measurement of Success: Treatment success was defined as elimination of menstruation (amenorrhea), or a significant reduction of flow to normal menstruation (cumenorrhea) or less than normal menstruation (hypomenorrhoea). Failed clinical outcome was defined as persistent menorrhagia.

Results : No intraoperative complications occurred and postoperative morbidity was minimal. At 12 months follow-up period, amenorrhea was achieved in 6 patients (25\%). Hypomenotrhea was achieved in 15 patients $(62.5 \%)$ and Eumenorrhea was achieved in 2 patients $(8.3 \%)$. Only one patient experienced a failed clinical outcome. The overall Comparison between pre and postoperative menstrual flow was highly significant .

Conclusion : Thermal balloon endometrial ablation is a sale, effective and easy technique in treatment of dysfunctional menorthagia.

Key words : Endometrial Ablation, Thermal Balloon: dysfunctional menorrhagia

\section{INTRODUCTION}

Menorrhagia is one of the most common gynecologic complaints ${ }^{(1)}$. The world health organization estimated that the worldwide prevalence of menorrhagia is as high as $19 \%$ of women in reproductive age ${ }^{(2)}$. Traditionally, the first line of treatment for dysfunctional menorthagia is the medical therapy. Failure of medical therapy, however, is an indication for surgical treatment.
For a long period, the available surgical treatment for dysfunctional menorrhagia was either the conservative dilatation and curettage or Hysterectomy. Although dilatation and curettage is the quickest way to stop acute bleeding specially in hypovolemic patients, yet it is a temporary treatment with a limited efficacy ${ }^{(3)}$. Hysterectomy, on the other hand, is the definitive surgical treatment, but it is a major operative procedure that could be associated with significant morbidity and mortality ${ }^{(4)}$. 
With the introduction of minimally invasive techniques, the surgical treatment options for dysfunctional menorrhagia has broadened. Initially, hysteroscopic surgery appeared to be the procedure of choice for treatment of menorrhagia.

Hysteroscopic endometrial ablation/resection is successful in controlling menorrhagia and, compared to hysterectomy, it is associated with less morbidity, mortality, shorter hospitalization and better recovery $(5,6)$.

The learning curve of hysteroscopic surgery however is substantial (7) and hysteroscopic surgery is not risk-free. Serious complications although few - are reported including fluid overload, uterine perforation, infection, hemorrhage, and thermal injuries to the surrounding structures $(6,8)$. O'Connor and Magos, reported an operative complication rate of $6 \%$ for patients undergoing their first procedure and a complication rate of $15 \%$ for repeat procedures $(6)$.

In an effort to simplify techniques and to reduce complications, a variety of non-hysteroscopic methods and devices were developed. In 1994, Neuwirth et al introduced the concept of thermal balloon ablation ${ }^{(9)}$. Since then, the procedure is gaining popularity day after day being with minimal learning curve, minimum complications, and the short and medium term cure-rate appears very promising $(10)$.

The aim of this study is to test the safety, effectiveness and short-term results of thermal balloon endometrial ablation in treatment of dysfunctional menorrhagia.

\section{MATERIALS \& METHODS}

Our study populations were patients between $40-50$ years of age complaining of menorhagia recruited form the inpatient section of obstetrics and gynecology department at Cairo University hospitals. The study extended from January 2002 to December 2003.

\section{Patient selection}

The recruited patients underwent a routine history taking, physical examination, pelvic examination and uterine sounding. Routine laboratory investigations were done including hemoglobin assay and coagulation profile. Pelvic ultrasound, diagnostic hysteroscopy and endometrial curettage ware done to every patient. A menstrual calendar was also done to record the number of flow days and the amount of flow per cycle.

Patients with established diagnosis of dysfunctional menorrhagia received appropriate medical treatment that extended for -at least- 3 cycles. Those with failed hormonal therapy and met the other inclusion criteria were enrolled in the study.

\section{Inclusion criteria}

- Excessive menstrual bleeding with the absence of organic lesions in the uterine cavity. Excessive menstrual bleeding was diagnosed if the patient complained of menstrual flooding, passage of blood clots and/or cycle length more than 7 days.

- Failed medical therapy

- Uterine cavity length less than $12 \mathrm{~cm}$

- A benign endometrial histology without atypia

\section{Exclusion criteria}

- Distortion of uterine cavity e.g. by septum or bicornuate uterus

- Intra-cavitary lesion c.g. submucous myoma or polyp 
- Atypical endometrial hyperplasia.

- Suspected genital tract infection or malignancy.

- Previous endometrial ablation

- A desire for further conception.

Patients who met our inclusion criteria were counseled about their treatment options. Those who agreed to be treated with thermal balloon ablation gave an informed consent. Out of 73 recruited patients, 24 patients were included in this study.

\section{Equipment}

We used THERMACHOICE ${ }^{\mathrm{TM}}$ uterine balloon therapy system (GYNECARE, Inc., Menlo Park, CA, USA). The apparatus consists of a 16-cm long, 4.5-mm diameter catheter with a latex balloon at its tip, housing a heating element. The catheter is connected to a control unit that maintains the temperature between $83-87^{\circ} \mathrm{C}$. The control unit also maintains the preset intra-balloon pressure and terminates the treatment after a preset time. For safety, the device automatically deactivates when the pressure falls below $45 \mathrm{~mm} \mathrm{Hg}$ or rises above $200 \mathrm{~mm} \mathrm{Hg}$.

\section{The treatment principle}

The principle of treatment is to use the thermal balloon as a heat transmission device to induce thermal injury to the endometrium along 7-9 minutes.

\section{Operative technique}

The patient was placed in the dorsal lithotomy position. General anaesthesia was given to all patients. The area of the vulva and vagina was cleansed and the patient was draped as usual. The urinary bladder was catheterized, and examination under anesthesia was performed. The cervix was exposed using a posterior vaginal wall retractor and grasped with a vulsellum. Dilatation of cervical canal till Hegar No. 5 was done in some cases to allow passage of the thermal balloon.

The thermal balloon was first, prepared by injecting and then withdrawing $5 \mathrm{ml}$ of $5 \%$ dextrose into its cavity. Then the balloon was inserted blindly into the dilated cervix and was gently advanced transcervically till it touches the uterine fundus.

The balloon was inflated with $5 \%$ dextrose in water. An average of $12-21 \mathrm{ml}$ was needed to inflate the balloon enough to fill the uterine cavity, and to create a stable intrauterine pressure between $160-180 \mathrm{~mm} \mathrm{Hg}$. The heater was then activated, and the fluid in the balloon was heated to $87^{\circ} \mathrm{C}$ and maintained for eight minutes to ablate the endometrium.

When the treatment cycle was complete, all the fluid was withdrawn from the balloon and the catheter was removed. The balloon was checked again for any leaks

\section{Postoperative care and follow-up}

Post-operative analgesia included piroxicam (Feldene ${ }^{(B)}$ ) rectal suppositories and tramadol $\left(\right.$ Tramal $\left.{ }^{(}\right)$intra-muscular injection when needed.

All women were discharged within 24 hours after the operation and reviewed after 6 weeks, 3 months, 6 months, and 12 months.

\section{Judging the outcome}

Treatment success was defined as elimination of menstruation (amenorrhea), or a significant reduction of flow to normal menstruation (eumenorrhea) or less than normal menstruation (hypomenorrhoea). Failed clinical outcome was defined as persistent menorrhagia. 


\section{Statistics}

Results were tabulated and analyzed on an IBM personal computer using Microsoft excel 2002 software on windows XP. Continuous data were expressed as mean $\pm \mathrm{SD}$. Comparison between the preoperative and postoperative menstrual flow was done using the paired Student's t-test. A "P" value of $<0.05$ was considered statistically significant

\section{RESULTS}

The study incorporated 24 patients with a mean age of $44.4 \pm 2.9$ (range from 40-50 years old) and mean parity of $4.9 \pm 1.72$ (range from 3-9). The mean uterine length was $9.8 \pm 1.27 \mathrm{~cm}$ (range from $8-12 \mathrm{~cm})$ and the mean fluid volume needed to inflate the balloon enough to attain the desired sustained pressure was $14 \mathrm{ml} \pm 1.79$ (range 12-21 $\mathrm{ml})$.

Table I : Comparison between pre and postoperative menstrual flow

\begin{tabular}{|l|c|c|}
\hline Flow (days) & $\begin{array}{c}\text { Pre-operative } \\
\text { Mean ( } \pm \text { SD) }\end{array}$ & $\begin{array}{c}\text { Post-operative } \\
\text { Mean }( \pm \text { SD) }\end{array}$ \\
\hline
\end{tabular}

$t$ value $=9.4408, \mathrm{df}=46, \mathrm{P}$ value $=<0.0001$

Table II : Menstrual pattern following thermal balloon endometrial ablation

\begin{tabular}{|l|c|c|c|}
\hline Menstrual pattern & $\begin{array}{c}\text { After 3 months } \\
\text { No. of patients }(\%)\end{array}$ & $\begin{array}{c}\text { After } 6 \text { months } \\
\text { No. of patients (\%) }\end{array}$ & $\begin{array}{c}\text { After 12 months } \\
\text { No. of patients (\%) }\end{array}$ \\
\hline Amenorrhea & $4(16.6)$ & $6(25)$ & $6(25)$ \\
\hline Hypomenorrhea & $20(83.3)$ & $16(66.6)$ & $15(62.5)$ \\
\hline Eumenorrhea & 0 & $2(8.3)$ & $2(8.3)$ \\
\hline Menorrhagia & 0 & 0 & $1(4.1)$ \\
\hline Total & $24(100)$ & $24(100)$ & $24(100)$ \\
\hline
\end{tabular}

Table I shows comparison between pre and postoperative menstrual flow days, while table II shows the postoperative menstrual pattern along a period of 12-month follow-up period. Only one patient in this study experienced a failed clinical outcome defined as persistent menorrhagia. None of the other patients required further therapy during the follow-up period.

Preoperatively, 5 patients (20.8\%) were complaining of dysmenorrhea. Only one patient continued to suffer from dysmenorrhea postoperatively. 
Two patients sufferred minor postoperative complications. One patient complained of hematuria, which subsided spontaneously within 48 hours. The other patient exhibited mild pyrexia with uterine tenderness, which was diagnosed as low-grade endometritis.

\section{DISCUSSION}

During the last decade, numerous minimally invasive surgical techniques were developed to treat dysfunctional menorrhagia as an alternative to hysterectomy. Although hysteroscopic guided endometrial resection/ablation is an established technique in controlling dysfunctional menorrhagia, yet the fairly long learning curve and the few but serious intra and postoperative complications limited its use to the highly trained endoscopist.

In our experience, the skill needed to ablate the endometrium using the thermal balloon technique is comparable to that of insertion of intrauterine contraceptive device, an opinion that is supported by others ${ }^{(11)}$. The very low learning curve, makes the procedure accessible to surgeons with minimal skills in endoscopy and junior staff as well.

In our study, no intraoperative complications were reported. One case sufferred postoperative hematuria, which disappeared spontaneously within 48 hours and another case, was given antibiotics to treat low-grade endometritis.

The safety record of the procedure and the low complication rates, were constantly reported by other authors in different studies $(10,11,12)$. Compared to other surgical procedures to treat dysfunctional menorrhagia, thermal balloon endometrial ablation appears to be the safest of all $(13,14,15)$.

Based on the definition of success adopted by this study, the overall success rate was $96 \%$ along the 12-month follow-up period. There was a statistically significant postoperative improvement in both menstrual pattern and dysmenorrhea as well.

Similar high success rates were recorded by other investigators $(10,11,12,13,14,15)$. However, long-term follow-up showed a slightly lower success rates ${ }^{(16)}$. Yet thermal balloon endometrial ablation remains superior over hysteroscopic guided endometrial resection/ablation techniques in term of achieving postoperative amenorrhea, hypomenorrhea, or eumenorrhea in both short and medium-term follow up $(13,15,17)$.

Proper balloon inflation is able to compress even a thick endometrium. This explains why using thermal balloon to ablate the endometrium without prior medical thinning was not found to make a significant difference in the outcome (18). In view of this fact, no medical or surgical pre-treatment endometrial thinning was used in the current study. Being able to avoid pre-treatment medical endometrial thinning agents such as Gn-Rh analogues, adds an advantage to the technique in term of cost reduction and to avoid possible drug side effects.

Preliminary studies demonstrated the safety and efficacy of thermal balloon endometrial ablation in medically and surgically risk patients $(19,20)$.

The ability to perform the technique under local anaesthesia (11), the short operating time, the lack of the need for a distending solution, and the 
minimal intra and postoperative complications nominates the thermal balloon endometrial ablation as the procedure of choice for medically and surgically high-risk patients.

During the 12-month follow-up period, 22 $(91.7 \%)$ patients expressed their satisfaction about the treatment outcome. Feitoza et al assessed the level of patient satisfaction about the treatment outcome following thermal balloon endometrial ablation. They found that $96 \%$ of patients were satisfied or very satisfied with the procedure (21). Comparing satisfaction rate between Hysteroscopic endometrial resection versus thermal endometrial destruction, Pellicano et al found that the patient satisfaction rate was significantly higher in the thermal endometrial destruction group (22). However, Jarrell and Olsen reported much lower patient satisfaction rate. They found that Less than $60 \%$ of women reported satisfaction with balloon endometrial ablation, and $40 \%$ underwent hysterectomy within I year of it ${ }^{(23)}$.

\section{CONCLUSIONS}

Thermal balloon endometrial ablation is gradually but confidently gaining popularity as a safe, effective, and easy technique in the treatment of dysfunctional menorrhagia.

Since most cases will not require cervical dilatation, and there is no need for direct endometrial visualization, or distension solution, we think that in the coming years the procedure could be done as an office procedure under local anaesthesia.

In fact, there is some concern that the minimally invasive nature, easiness, safety, and fewer complication rate of thermal balloon endometrial ablation may lead to overuse of the technique to include milder cases of menorthagia that otherwise could be treated medically ${ }^{(24)}$. We think that sticking to patient selection criteria like that presented in this study will lessen such concern.

\section{ACKNOWLEDGEMENT}

The authors would like to acknowledge the generous contribution of GYNECARE Egypt for supplying the THERMACHOICETM Uterine Balloons used in this research work. The authors would also like to thank Doctor Hidy Alfred of GYNECARE Egypt for her assistance and support.

\section{REFERENCES}

1- Stabinsky SA, Einstein M, Breen JL. Modern treatments of menorrhagia attributable to dysfunctional uterine bleeding. Obstet Gynecol Surv, 1999 Jan 54:1 pp 61-72.

2- Snowden R, and Christian B. Patterns and Perception of Menstruation: a World Health Organization International Study. London: Croom Helm; 1983.

3- March CM, and Brenner PF. Dysfunctional uterine bleeding In: Lobo RA, Mishell DR, Pauldon RJ, and Shoupe D. (eds.) Infertility, contraception, and reproductive endocrinology. Blackwell Science, 1997: pp 384-402.

4- Varol N, Healey M, Tang P, Sheehan P, Maher P, and Hill D. Ten-year review of hysterectomy morbidity and mortality: can we change direction? Aust N Z J Obstet Gynaecol 2001 Aug 4l: pp 295-302.

5- Garry R, Shelley-Jones D, Mooney P, and Phillips G. Six hundred endometrial laser ablations. Obstet. Gynecol. 1995, 85, pp 24-29. 
6- O'Connor, H. and Magos, A. Endometrial resection for the treatment of menorrhagia. N. Engl. J. Med. 1996, 335, pp 151-156.

7- Davis, J.A. Hysteroscopic endometrial ablation with the neodymium-YAG laser. Br. J. Obstet. Gynaecol. 1989, 96, pp 928-932.

8- Vilos GA, D'Souza I, and Huband DJ. Genital tract burns during rollerball endometrial coagulation. Am Assoc Gynecol Laparosc 1997 Feb 4:2 pp 273-6.

9- Neuwirth RS, Duran AA, Singer A, MacDonald R, and Bolduc L. The endometrial ablator: a new instrument. Obstet. Gynecol. 1994, 83, pp 792-796.

10- Amso NN, Stabinsky SA, McFaul P, Blanc B, Pendley L, Neuwirth R. Uterine thermal balloon therapy for the treatment of menorrhagia: the first 300 patients from a multi-center study. International Collaborative Uterine Thermal Balloon Working Group. Br J Obstet Gynaecol 1998 May 105: pp $517-23$

11- Fernandez H, Capella S, and Audibert F. Uterine thermal balloon therapy under local anaesthesia for the treatment of menorrhagia: a pilot study.Human Reproduction. 1997 vol.12 no.11 pp. 2511-2514.

12- Gallinat A. Endometrial ablation by balloon coagulation. Contrib Gynecol Obstet 2000; 20: $137-44$

13- Gervaise A; Fernandez H; Capella-Allouc S; Taylor S; Vieille SL; Hamou J; and Gomel V. Thermal balloon ablation versus endometrial resection for the treatment of abnormal uterine bleeding. Hum Reprod 1999 Nov; 14(11): 2743-7

14- Barrow C. Balloon endometrial ablation as a safe altcrnative to hysterectomy. AORN J 1999 Jul; 70 (1): 80, 83-6, 89-90; quiz 92-6

15- Van Zon-Rabelink IA; Vleugels MP; Merkus HM; and De Graaf R. Endometrial ablation by rollerball electrocoagulation compared to uterine balloon thermal ablation. Technical and safety aspects. Eur $J$ Obstet Gynecol Reprod Biol 2003 Oct 10; 110(2): 220-3.

16- Amso NN; Fernandez H; Vilos G; Fortin C; McFaul P; Schaffer M; et al. Uterine endometrial thermal balloon therapy for the treatment of menorrhagia: long-term multicentre follow-up study. Hum Reprod 2003 May; 18(5): 1082-7.

17- Grainger DA; Tjaden BL; Rowland C; and Meyer WR. Thermal balloon and rollerball ablation to treat menorrhagia: two-year results of a multicenter, prospective, randomized, clinical trial. Am Assoc Gynecol Laparosc 2000 May; 7(2): 175-9.

18- Lissak A, Fruchter O, Mashiach S, Brandes-Klcin $O$, Sharon A, Kogan $O$, et al. Immediate versus delayed treatment of perimenopausal bleeding due to benign causes by balloon thermal ablation. J Am Assoc Gynecol Laparosc 1999 May 6:2 145-50

19- Aletebi FA; Vilos GA; and Eskandar MA. Thermal balloon endometrial ablation to treat menorrhagia in high-risk surgical candidates. J Am Assoc Gynecol Laparosc.1999 Nov;6(4): 435-9.

20- Soysal M; and Soysal SK. Endometrial thermal balloon ablation under local anesthesia in patients with prosthetic heart valves: a pilot study. Zentralbl Gynakol 2000; 122(11): 556-60.

21- Feitoza SS; Gebhart JB; Gostout BS; Wilson TO; and Cliby WA. Efficacy of thermal balloon ablation in patients with abnormal uterine bleeding. Am J Obstet Gynecol 2003 Aug; 189(2): 453-7.

22- Pellicano M; Guida M; Acunzo G; Cirillo D; Bifulco G; and Nappi C. Hysteroscopic transcervical endometrial resection versus thermal destruction for menorrhagia: a prospective randomized trial on 
satisfaction rate. Am J Obstet Gynecol 2002 Sep; 187(3): $545-50$

23- Jarrell A; and Olsen ME. Patient satisfaction with thermal balloon endometrial ablation. A retrospective review. J Reprod Med 2003 Aug; 48
(8): $635-6$

24- Health Technology Advisory Committee i Minnesota. Surgical Alternatives to Hysterectomy for Abnormal Uterine Bleeding. Physician Report, June 2000. 